Sharif, A.M. (1997). "The Management of Intelligence-Assisted Finite Element Analysis Technology". In Proc. Portland International Conference on Management of Engineering and Technology(PICMET'97), Portland, Oregon, July $27^{\text {th }}-31^{\text {st }}$ 1997, Portland, OR : Portland State University / IEEE / Informs, pp.2550-2555.

\title{
The Management of Intelligence-Assisted Finite Element Analysis technology
}

\author{
Amir Sharif \\ Centre for Neural and Evolutionary Systems (CNES) \\ Dept. of Computer Science and Information Systems \\ Brunel University \\ Uxbridge, Middlesex, UB8 3PH, UK
}

\begin{abstract}
Artificial Intelligence (AI) approaches to Finite Element Analysis (FEA), have had tentative degrees of success over the last few years and some authors have argued that effective FEA can help in the manufacture reliability and safety aspects of engineered artefacts. The author of this paper reviews how such AI techniques have been applied and in this light, the author then uses a Fuzzy Cognitive Mapping (FCM), to develop a framework for the management of intelligence-assisted FEA.
\end{abstract}

\section{INTRODUCTION}

In the design and manufacture of many engineering artefacts, Computer Aided Design (CAD) packages often employ the Finite Element Method (FEM) as a numerical analysis tool for finding physical quantities such as heat, stress and displacement for a particular design. This is achieved by producing an FE (Finite Element) 'mesh' of elements which tessellate together, in a structured or unstructured manner ([29], [36], [44], [70]) within the boundaries of the engineering component model and this process is called Finite Element Mesh Generation (FEMG).

However, the effective modelling and management of FE models and results is, in its simplest form, an arcane task [12]. Software implementations of the method, can sometimes be needlessly verbose and technical, so much so that even experts find difficulty in the modelling of relatively straightforward problems ([10], [12], [30], [52], [68]). Using previous knowledge and interrelationships between model parameters, to overcome such problems does not mean that such a technique is always adaptable to new design scenarios ([15], [16], [27], [46], [51]).

It is evident from the literature that in order to utilise such modelling and computational analysis techniques for the design and manufacture of engineering components, requires some method of harnessing and managing CAD and FEA expertise. Effective use of these computerised approaches to design and analysis should ensure greater reliability and safety of manufactured products from an increased emphasis on design assistance. What is therefore required, is a means by which assistance can be given to the FEM / FEMG process, as and when required [8]. To achieve this, methods such as Knowledge Based Expert Systems [37], Neural Networks [2], Fuzzy Logic
([45], [84]) and Genetic Algorithms ([31], [35]), have attempted to answer such problems and have been tentatively applied to the FEM and FEMG in the last 1015 years. This paper reviews and outlines how each AI technology has helped in FEA problems that require FEMG, and by the use of a cognitive mapping, a framework for future AI-based FEA is presented.

\section{A CLASSIFICATION OF AI METHODS APPLIED TO FINITE} ELEMENT ANALYSIS

A classification and taxonomy of each AI method, as discussed previously, is given in Table I with references to Knowledge Based Expert Systems (KBES), Neural Networks (NN), Fuzzy Logic (FL) and Genetic Algorithms (GA) applications.

Expert Systems are generally used to guide the user through the modelling process, by posing questions related to how the user wants to define and analyse the model problem ([33], [48], [55], [56], [76]). A typical KBES architecture for CAD/FEA includes a knowledge 'blackboard' where current information relating to the modelling of the problem is updated, from various solution sources [72].

Fuzzy logic has been used more as an assistant to other applied AI techniques within FE implementations. This has mostly been in the shape of interpreting and quantifying verbose and imprecise definitions of elicited knowledge and constructs and so is only used as a type of data filtering tool ([79], [80]). If combined with a KBES ([67], [77]) it can provide a versatile means to control both engineering judgement and the modelling of the realworld artefact.

Neural Network and Genetic Algorithm implementations have been to a much more limited extent within FEA and FEMG and have mostly been confined to evolutionary growth of an FE mesh and associated shape optimisation([1], [3], [14], [17], [38], [60], [71]). Each paradigm has its advantages and limitations and so any future FEA package/design tool that wishes to achieve the ideals of a perfect FE implementation [10] should try to take into account the feasibility of incorporating such methods based on their limitations rather than their advantages [32]. 
Sharif, A.M. (1997). "The Management of Intelligence-Assisted Finite Element Analysis Technology”. In Proc. Portland International Conference on Management of Engineering and Technology(PICMET'97), Portland, Oregon, July $27^{\text {th }}-31^{\text {st }}$ 1997, Portland, OR : Portland State University / IEEE / Informs, pp.2550-2555.

TABLE I TAXONOMY OF AI TECHNIQUES APPLIED TO FEA

\begin{tabular}{|c|c|c|c|c|}
\hline & \multicolumn{4}{|c|}{ AI TECHNOLOGY } \\
\hline CHARACTERISTIC & KBES & $N N$ & $F L$ & $G A$ \\
\hline Mechanism & IF...THEN...ELSE & $\begin{array}{l}\text { Activation / Threshold } \\
\text { function (ramp, sigmoid) }\end{array}$ & IF...THEN...ELSE & $\begin{array}{l}\text { Genetic Operators } \\
\text { (crossover, mutation, etc) }\end{array}$ \\
\hline Envelope & Domain Knowledge & Input data & Closed interval, i.e. $[0,1]$ & Population size \\
\hline Advantages & $\begin{array}{l}\text { Uses knowledge representation, } \\
\text { to reason solution via inference } \\
\text { engine }\end{array}$ & $\begin{array}{l}\text { Human brain analogue, } \\
\text { ability to learn and } \\
\text { recognise patterns }\end{array}$ & $\begin{array}{l}\text { Models vague / imprecise } \\
\text { information ('quantifies the } \\
\text { unquantifiable') }\end{array}$ & $\begin{array}{lcc}\begin{array}{l}\text { Finds } \\
\text { obtains } \\
\text { solution }\end{array} & \begin{array}{c}\text { best } \\
\text { best }\end{array} & \text { 'natural' } \\
\end{array}$ \\
\hline Limitations & $\begin{array}{l}\text { Brittle, specialised domain } \\
\text { application, long development } \\
\text { time required }\end{array}$ & $\begin{array}{l}\text { Network architecture } \\
\text { difficult to design } \\
\text { computationally intensive }\end{array}$ & $\begin{array}{l}\text { Modelling is fuzzy in itself, } \\
\text { oversimplifies domain } \\
\text { knowledge }\end{array}$ & $\begin{array}{l}\text { Computationally intensive, } \\
\text { not applicable to all } \\
\text { optimisation problems }\end{array}$ \\
\hline Application to FEA & $\begin{array}{l}\begin{array}{l}\text { Increase model } \\
\text { representation }\end{array} \\
\begin{array}{l}\text { knowledge } \\
\text { (Feature }\end{array} \\
\begin{array}{l}\{11],[15],[16],[22],[24], \\
{[28],[33],[39],[40],[49],[50],} \\
{[54],[[57],[59],[77],[82]\}}\end{array}\end{array}$ & $\begin{array}{l}\text { Quicker convergence of } \\
\text { solutions based on 'learnt' } \\
\text { Mesh patterns } \\
\{[1],[3],[15],[16],[18], \\
[38],[42],[58],[71],[81]\}\end{array}$ & $\begin{array}{l}\text { Modelling of vague } \\
\text { imprecise B.C.'s / Geometry } \\
\{[69], \quad[74], \quad[78], \quad[79], \\
[80]\}\end{array}$ & $\begin{array}{l}\text { Optimisation of model } \\
\text { variables (mesh element } \\
\text { size, model geometry) } \\
\{14],[17],[25],[43],[60] \text {, } \\
[73]\}\end{array}$ \\
\hline
\end{tabular}

\section{DEVELOPMENT OF A COGNITIVE MAPPING FOR} MESH GENERATION

A cognitive mapping for the FEM is now presented, which entails detailing the nature of how each AI technique has been and could be applied to FEMG in particular. This is done so as to develop a framework for incorporating AI within the FEA process (see Section IIIB). The FCM presented here is merely a conceptual mapping not intending to be based on any mathematical background and a more rigorous appraisal of the mathematical basis of FCMs can be found in Simpson [64].

\section{A. An FCM for FEMG}

A Fuzzy Cognitive Map (FCM) is a technique that can be used to associate different events and processes via causal rules, which is similar to other 'mind maps' used in psychology ([7], [45]). Essentially, FCMs are nonhierarchic flow charts, within which a series of concepts are linked to other such concepts via associations which are more quantitative than qualitative (i.e. fuzzy / vague linguistic statements such as 'usually', 'not often', 'sometimes').

An FCM which shows the current application of AI techniques to FEM and FEMG, is produced in Figure 1 to elucidate how each technique fits into the FEA process [63]. In what follows, concepts relating to one another are written with their associated fuzzy quantifiers such :

$$
<\text { concept_1> } \quad \rightarrow \quad<\text { concept_2> [quantifier] }
$$

where the quantifier can be a causal increase or decrease related further to a quantifier (e.g. "sometimes", "maybe", etc). The arrow $(\rightarrow)$ denotes the direction the statement is read in and the FCM can be read in any direction, from any starting node. For example the statement : " Non-linear nodal density distribution $\rightarrow$ Element clustering + always" might be read as "non-linear nodal density distribution always causes an increase in element clustering". The words 'model' and 'problem' relate to FEA scenarios which an analyst may encounter.

From the FCM in Fig.1, the following statements can be produced in a similar fashion in the light of literature which discusses deficiencies of the FEM (references [8],[12], [52], [68]) which are listed in Table II.

TABLE II

a) Problems outside of the knowledge domain may lead to inconsistent / vague assumptions about system variables (i.e. KBES $\rightarrow$ FL - sometimes).

b) KBES's can allow the user to interrogate and define problems within the confines of the knowledge domain, so that geometric representations can lead to successful FE meshes (i.e. KBES $\rightarrow$ FEMG ALGORITHM + geometry).

c) KBES's could assist in steering the solution path of a GA towards realistic and known optima (results), retaining as much design information as possible within the evolved solutions (i.e. KBES $\rightarrow \mathrm{GA}+$ sometimes).

d) FL can help to elucidate unquantifiable engineering judgement parameters that can sometimes lead to increased accuracy of modelling the real-world problem (i.e. FL $\rightarrow$ KBES + mostly).

e) The imposition of boundary conditions can be easily facilitated using FL to quantify non-linear and irregular phenomena/features which cannot easily be suggested in numerical terms (i.e. FL $\rightarrow$ FEMG ALGORITHM +). f) NN's can assist in the development of a finite element mesh from examples (training data) using selforganising or self-regulating neural architectures (i.e. $\mathrm{NN} \rightarrow$ FEMG ALGORITHM +).

g) Optimisation of model problem in terms of either its geometry, finite element nodal distribution, or feature detail, can be achieved by using GAs whereby a geometric (shape) optimisation provides a basis for an effective mesh generation (i.e. GA $\rightarrow$ FEMG ALGORITHM +). 
Sharif, A.M. (1997). "The Management of Intelligence-Assisted Finite Element Analysis Technology". In Proc. Portland International Conference on Management of Engineering and Technology(PICMET'97), Portland, Oregon, July $27^{\text {th }}-31^{\text {st }}$ 1997, Portland, OR : Portland State University / IEEE / Informs, pp.2550-2555.

h) A neural network's efficiency can be greatly improved by employing a GA search for an optimal neural architecture (i.e. $\mathrm{GA} \rightarrow \mathrm{NN}+$ sometimes).

\section{B. AI within the FEA process}

Combining the FCM presented in Figure 1 with Table II, we can categorise where each AI technology falls within the traditional FEA process as shown in Figure 2. In this process, the user defines a geometric model (the artefact) which is to be analysed by the FEM by producing a mesh for it and subsequently computing and visualising the results (GRAPHICAL VISUALISATION).

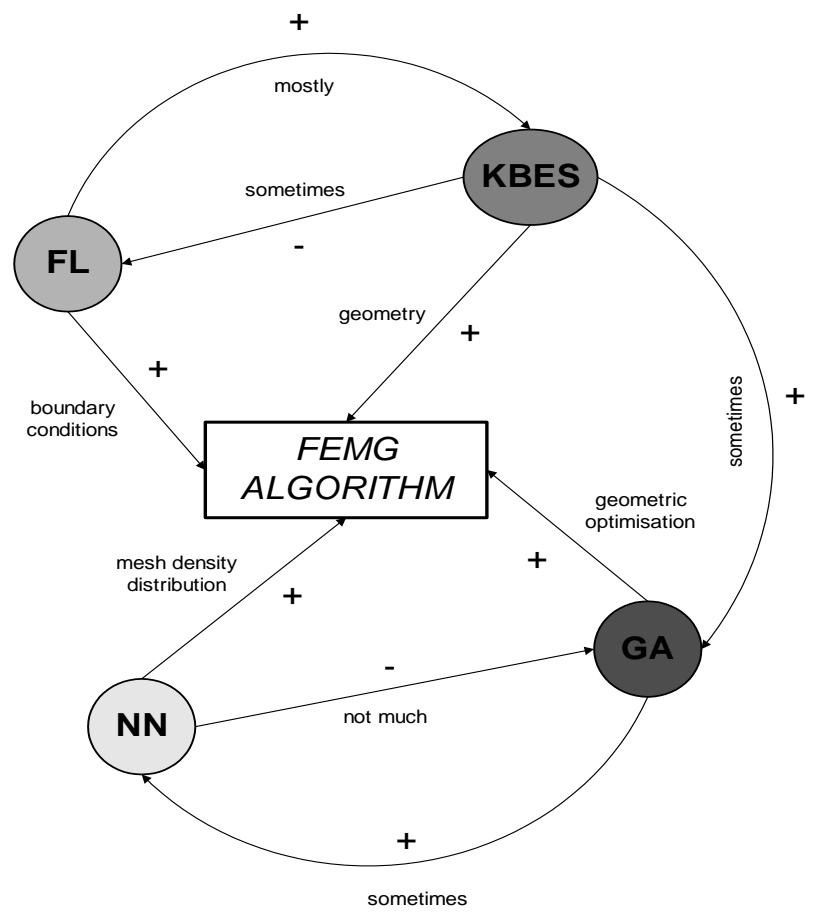

Fig. 1 An FCM for Finite Element Mesh Generation via AI-driven paradigms

As an aid to the FEA process, each AI technique assists the user in managing data input and the modelling and analysis of results tasks. This AI-based FEA process increases the understanding of the fundamentals of a problem to be modelled, by the assisted definition of geometry, boundary conditions, and selection of solution controls.

Within the context of Figure 2, a KBES may help to elucidate the required solution technique of the problem (GEOMETRY MODEL), via a known representation for a particular problem e.g. 2D / 3D, linear, bilinear, plate or shell elements (as in PLASHTRAN [11]). In defining the model problem, user knowledge which can help to clarify details of the geometric model could be augmented by fuzzy definitions of boundary conditions, (PHYSICAL MODEL), as Valliapan \& Pham have demonstrated [74]. Subsequent changes in the knowledge domain can then be updated by the knowledge of a physical model so that the
KBES becomes more of a FKBES (Fuzzy KBES, as in Soh \& Yang [67]).

'Intelligent' meshing strategies could encompass notions of mesh adaption, in line with standard numerical measures for mesh adaptivity ([9], [21], [53], [86]) by using NNs or GAs for these tasks (see Table 1, NN and GA columns). The 'intelligence' of such a procedure would lie with locating and selecting those elements in the mesh which had large errors and also with the adaptive procedure itself.

Generating an optimal mesh for the solution of the numerical quantities discussed in Section I is important, since the performance of the FE computation can rely heavily on the 'neatness' of the underlying equations which describe the quantities being sought and the FE tessellation (especially for Kohonen's SOM tessellation [21], [23]). To this end, a GA search of all possible mesh element tessellation / nodal density distributions that provide a low error measure (as described by Babuska \& Miller [9] and Zienkiwicz \& Zhu [86]), may provide meshes which could be more adaptable than numerically adaptive ones [71]. This is of course at the expense of computational overheads, which for some problems, can be expensive ([7], [31], [42]).

$\mathrm{NN}$ or GA techniques aid in the production of an FE mesh remains to be a moot point and a case for further investigation such as in the modal analysis of optical waveguide devices ([20], [62]). The whole FEA picture can be assisted by AI techniques, in the form of managing user information which translates a real world problem to a real world solution. The underlying notion of the process then becomes are of increasing the knowledge of not only the problem being modelled (by elicitation, KBES, and quantification, FL) but also of the generation of approximate domain solutions (by optimisation, $\mathrm{NN}$ and GA).

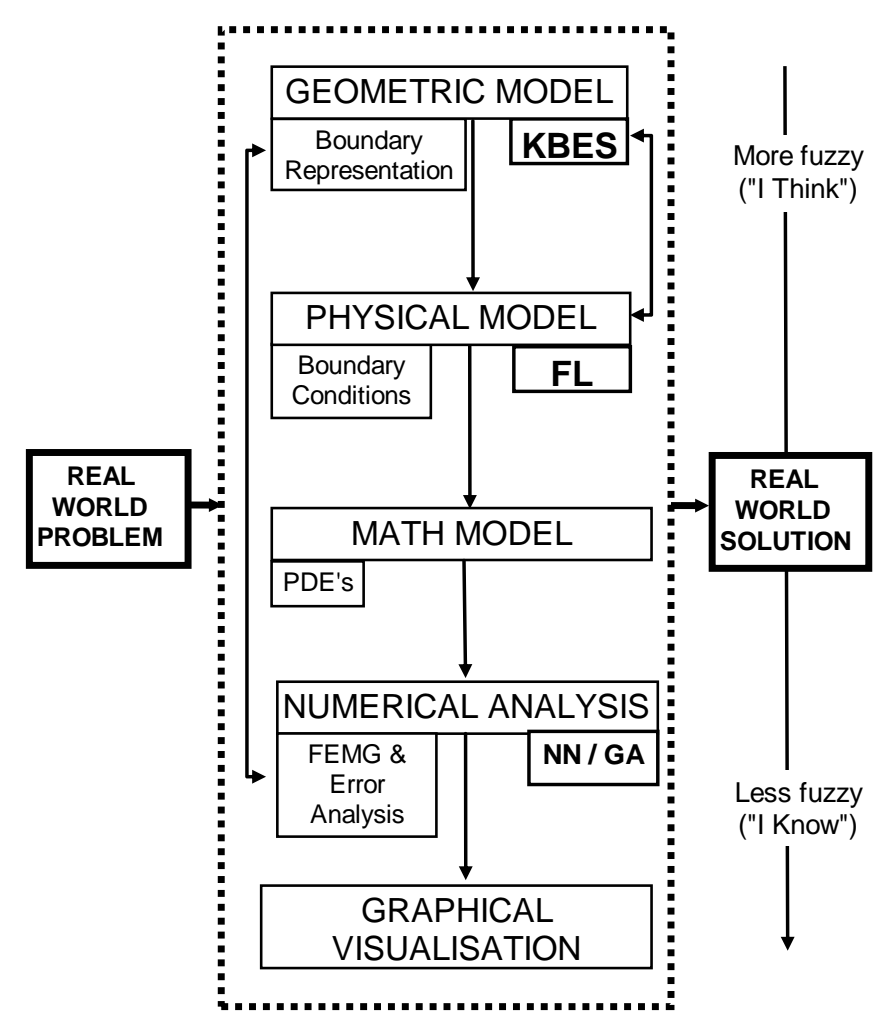


Sharif, A.M. (1997). "The Management of Intelligence-Assisted Finite Element Analysis Technology". In Proc. Portland International Conference on Management of Engineering and Technology(PICMET'97), Portland, Oregon, July $27^{\text {th }}-31^{\text {st }}$ 1997, Portland, OR : Portland State University / IEEE / Informs, pp.2550-2555.

Fig.2 AI within the FEA process (after Finn [22] ; Sharif [61]; Shephard [63])

\section{CONCLUSIONS}

A FCM (Fuzzy Cognitive Map) was presented in this paper which helped in showing where each reviewed AI paradigm can have its successful application to Finite Element Analysis, via managing knowledge of the problem being modelled. It was argued that the process of modelling real-world CAD/FEA problems consists of moving from a state of not-knowing enough about how best to model the problem, to knowing how to model it in any future scenarios (as in Figure 2), using elicitation (KBES), quantification (FL) and optimisation (NN or GA) to manage the modelling of an engineering artefact. It is therefore hoped that the emerging AI paradigms looked at in this paper can be organised in such a fashion as to modelling and analysis procedures better via some form of interactive assistance (such as in the development of Problem Solving Environments, [6], [26]).

\section{REFERENCES}

[1] C.H. Ahn, S.S Lee, H.J. Lee, and S.Y.A. Lee, "A self-organizing neural network approach for automatic mesh generation", IEEE Trans. Magnetics, vol.27, \#5, pp4201-4203, 1991

[2] I. Aleksander and H. Morton, An Introduction to Neural Computing, London : Chapman and Hall, 1990

[3] S. Alfonzetti, S. Coco, S. Cavalieri and M. Malgeri, "Automatic mesh generation by the Let-It-Grow Neural-Network", IEEE Trans. Magnetics, vol.32, \#3, pp1349-1352, 1996

[4] A.E. Andrews,"Progress and challenges in the application of artificial intelligence to Computational Fluid Dynamics", AIAA J., vol. 26, \#1, pp 40-46, 1988

[5] J.H. Argyris, Energy Theorems and Structural Analysis, London : Butterworth, 1960

[6] J.H. Argyris, I. St. Doltsinis, G. Frik, and L. Tenek, "Computational structures technology in Europe", IEEE Comp. Sci. Eng., Spring 1994, pp43-54

[7] R. Axelrod, Structure of Design, CA : Princeton University Press, 1976

[8] I. Babuska, "New problems and trends in the Finite Element Method", in Proc. Conf. on the Mathematics of Finite Elements (MAFELAP '96), Brunel University, Uxbridge, UK, 9-12 June 1996, J.R. Whiteman, Ed., To appear

[9] I. Babuska and A. Miller, "The post-processing approach in the Finite Element Method - Part3 : A-posteriori error estimates and adaptive mesh selection", Int. J. Num. Meths. Eng., vol.20, pp2311-2324, 1984

[10]I. Babuska and W. Rheinboldt, "Computational aspects of the Finite Element Method", in Mathematical Software III, J.R. Rice, Ed., NY : Academic Press, pp225-255, 1977

[11]J. Cagan and V. Genberg, "PLASHTRAN : An expert consultant on Two-Dimensional Finite Element modelling techniques", Eng. Comput.,vol.2, pp199-208, 1987

[12]R.B. Clarke and D.J. Robinson, "Effective use of Finite Element Analysis techniques within an integrated CADCAM system", in Effective CADCAM 1985, IMechE, pp33-38, 1985

[13]P.K. Coats, "A critical look at Expert Systems for business information applications", J. Info. Tech., vol.6, pp208-216, 1991

[14]P. Cuesta, Adaptive Mesh Generation in non-convex domain and applications, Doctoral Dissertation, University Las Palmas de Gran Canaria, Spain, 1992
[15]B. Dolsak and A. Jezernik, "Mesh Generation expert system for engineering analyses with FEM", Comp. Ind., vol.17, \#2-3, pp 309315,1991

[16]B. Dolsak, A. Jezernik, A and I. Bratko, "A knowledge-base for FiniteElement Mesh design", AI Eng., vol. 9, \#1, pp19-27, 1994

[17]D. Doorly, "Parallel Genetic Algorithms for optimisation in CFD", in Genetic Algorithms in Computer Science and Engineering, G. Winter, J. Periaux, M. Galan and P. Cuesta, Eds., John Wiley, pp.251270, 1995

[18]D.N. Dyck, D.A. Lowther, and S. McFee, "Determining an approximate Finite Element mesh density using neural network techniques", IEEE Trans. Magnetics, vol.28, \#2, pp1767-1770, 1992

[19]R.D. Ettinger, F.A. Fernandez, F.A. and J.B. Davies, "Application of adaptive remeshing techniques to the finite element analysis of nonlinear optical waveguides", in Directions in Electromagnetic Wave modelling, H.L. Bertoni and L.B. Felsen, Eds., NY : Plenum Press, 1991

[20]F.A. Fernandez and Y. Lu, Microwave and Optical Waveguide analysis by the Finite Element Method, Chichester : Research Studies Press / John Wiley, 1996

[21]M. Filipiak, Mesh Generation (Technology in Focus document). [Online] Available : http ://www.epcc.ed.ac.uk/epcc-tec/documents.html, 1996

[22]D.P. Finn, "A Physical modelling assistant for the preliminary stages of Finite Element Analysis", AI Eng. Des. Anal. Manuf., vol.7, \#4, pp275-286, 1993

[23]J.-C. Fort and G. Pages, "About the Kohonen Algorithm : Strong or Weak self-organisation?", Neural Networks, vol.9, \#5, pp773-785, 1996

[24]R. Fruchter, J. Gluck, J. and Y.I. Gold, "Application of AI Programming techniques to the analysis of structures", in Proc. $3^{\text {rd }}$ Int. Conf. Civil and Struct. Eng. Comp., CIVIL COMP '87, Civil-Comp Press, pp99-103, 1987

[25] M. Galante, "Genetic Algorithms as an approach to optimize real-world Trusses", Int. J. Num. Meths. Eng., vol.39, pp361-382, 1996

[26]E. Gallopoulos, E. Houstis and J.R. Rice,"Computer as Thinker / Doer : Problem-Solving Environments for computational science", IEEE Comp. Sci. Eng., Summer, pp11-23, 1994

[27]M.R. Genesereth and N.J. Nilsson, Logical foundations of Artificial Intelligence, Morgan Kaufmann, 1988

[28]C. Gengdong, and Y. Zeng, Strategies for Automatic Finite Element modelling, Comp. Struct., vol.44, \#4, pp905-909, 1992

[29]P.L. George, Automatic Mesh Generation, London : John Wiley, 1991

[30]J.F. Gloudeman, "Future Finite Element software systems", AMD (Symposia Series), vol. 75, pp 449-458, ASME, 1986

[31]D.E. Goldberg, Genetic Algorithms in Search, Optimisation and Machine Learning, MA : Addison Wesley, 1989

[32]S. Goonatilake and S. Khebbal, Intelligent Hybrid Systems, London : John Wiley, 1994

[33]D.E. Grierson and G.E. Cameron, "A Knowledge-based expert system for computer automated structural design", in Proc. $3^{\text {rd }}$ Int. Conf. Civil and Struct. Eng. Comp., CIVIL COMP '87, Civil-Comp Press, pp9397, 1987

[34]P. Hammond and J.C. Davenport, "Eliciting and modelling the design knowledge of multiple experts", Dept. of Computer Science \& Information Systems, Brunel University, Technical Report CSTR-954, pp1-15, 1994

[35]J.H. Holland, "Genetic Algorithms", Scientific American, 267(1), pp66-72, 1992

[36] K. Ho-Le, "Finite Element mesh generation methods", CAD, vol.20, \#1, pp27-38, 1988

[37]P. Jackson, Introduction to Expert Systems, Addison-Wesley, 1990

[38] M.N. Jadid and D.R. Fairbairn, "The application of Neural-Network techniques to Structural Analysis by implementing an Adaptive Finite Element mesh generation", AI Eng. Des. Anal. Manuf., vol.8, \#3, pp177-191, 1994

[39] K. Jambunathan, E. Lai, S.L. Hartle and B.L. Button, "Development of an intelligent front end using LISP", in Applications of Artificial Intelligence in Engineering, pp228-243, Computational Mechanics Publications, 1992

[40]E. Kang, and K. Haghighi, "Intelligent Finite Element mesh generation", Eng. Comps., vol.11, \#2, pp70-82, 1995

[41] H. Kardestuncer, and D.H. Norrie, Finite Element Handbook, NY Mcgraw-Hill, 1984 
Sharif, A.M. (1997). "The Management of Intelligence-Assisted Finite Element Analysis Technology". In Proc. Portland International Conference on Management of Engineering and Technology(PICMET'97), Portland, Oregon, July $27^{\text {th }}-31^{\text {st }}$ 1997, Portland, OR : Portland State University / IEEE / Informs, pp.2550-2555.

[42]A.I. Khan and B.H.V. Topping, "Parallel training of Neural Networks for Finite Element mesh generation", in Neural Networks and Combinatorial Optimization in Civil and Structural Engineering, B.H.V. Topping and A.I. Khan, Eds. Civil-Comp Press, pp.81-94, 1993

[43] J. Kim, H.B. Lee., H.K. Jung, S.Y. Hahn, C. Cheon, and H. Kim, "Optimal design technique for Waveguide device", IEEE Trans. Magnetics, vol.32, \#3, pp.1250-1253, 1996

[44]P. Knupp, and S. Steinberg, Fundamentals of Grid Generation, FL : CRC Press, 1994

[45]B. Kosko, Fuzzy Thinking : The new science of Fuzzy Logic, Flamingo Press, 1990

[46]R. Kowalski, Logic for Problem Solving, North-Holland, 1990

[47]J.R. Koza, "Introduction to Genetic Programming", in Advances in Genetic Programming, K.E. Kinnear Jr., Ed., MA : MIT Press, pp2142,1994

[48]C.S. Krishnamoorthy and R. Krishnakumar, "Knowledge-Based Expert Systems for Finite Element Analysis", in Finite Element Analysis for Engineering Design (Lecture Notes in Engineering \#37), J.N. Reddy, C.S. Krishnamoorthy and K.N. Seetharamu, Eds., Springer-Verlag, pp842-859, 1988

[49]R. Labrie, C. Thilloy, P.A. Tanguy and G.H. Moll., "An Expert assistant to monitor Finite Element simulations", Math. Comp. Sim., vol.36, \#4-6, pp413-422, 1994

[50]P. Laug, "DOMINO : a Knowledge-based system for the users of a Finite Element library", Math. Comp. Sim., vol.36, pp293-301, 1994

[51] N. Lavraz, and S. Dzeroski, "Finite Element Mesh design", in Inductive Logic Programming : Techniques and Applications, Ellis Horwood, pp217-225, 1994

[52]J.K. Liker, M. Fleischer, and D. Arnsdorf, "Fulfilling the promises of CAD", Sloan Man. Rev., Spring 1992, pp74-86, 1992

[53]T.J. Liszka, "An introduction to $h-p$ adaptive Finite Element Method", Available [on-line], http://www.comco.com/main/reports/hpintro/hpintro.html, 1995

[54]Y.C. Liu, H.A. EI-Maraghy and K.F. Zhang, "Expert system for forming Quadrilateral Finite Elements", Eng. Comps., vol.7, \#3, pp249-257, 1990

[55] J. Mackerle, and K. Orsborn, "Expert systems for Finite Element Analysis and design optimisation - A review", Eng. Comps., vol.5, pp90-102, 1988

[56] B.P. Naganarayana and G. Prathap, (1992) "Expert Systems and Finite Element Structural Analysis - A review", Sadhana Academy Proceedings in Engineering Sciences, National Aeronautics Lab., Bangalore University, India, vol.17, \#2, pp275-298, 1992

[57]E. Rank and I. Babuska, "An Expert System for the optimal mesh design in the hp-version of the finite element method", Int. J. Num. Meths. Eng., vol.24, pp2087-2106, 1987

[58]L. Rao, B. He, and W. Yan, "Novel adaptive generator based on Kohonen's Neural Network model and vector quantization", in Proc. $2^{\text {nd }}$ Int. Conf. Computation in Electromagnetics, April 12-14 1994, Nottingham, UK, , IEE Conference \#384, pp193-197, 1994

[59]K. Reichert, J. Skoczylas, and T. Tarnhuvud, "Automatic Mesh Generation based on Expert System Methods, IEEE Trans. Magnetics, vol.27, \#5, pp4197-4200, 1994

[60]K. Sanada, C.W. Richards, D.K. Longmore and D.N. Johnston, "Finite element model of hydraulic pipelines using an optimized interlacing grid system", J. Cont. Sys. Eng., vol.207, \#4, pp213-201, 1993

[61] A.M. Sharif, "Finite Element Mesh Generation and CAD research : Progress report, November 1995", Dept. of Computer Science and Information Systems, Brunel University, UK, Working paper, 1995

[62] A.M. Sharif, "AI Techniques in Finite Element Mesh Generation : Optical Waveguide Design and Analysis, Progress Report October 1996", Dept. of Computer Science and Information Systems, Brunel University, UK, Working paper, 1996

[63]M.S. Shephard, "Finite Element Modelling within an Integrated Geometric Modelling Environment : Part I \& II", Eng. Comput., vol.1, pp61-85, 1985

[64]H.A. Simon, "Artificial Intelligence : an empirical science", AI, vol. 77, pp95-127, 1995

[65]P.K. Simpson, Artificial Neural Systems : Foundations, Paradigms and Applications, NY : Mcoraw-Hill, 1990

[66]M. Soerensen and G. Boehmler, "The Missing link between CAD and FEM - does it exist?, Finite Elements in Computational Mechanics (FEICOM '85), Vol.2, T. Kant, Ed., Pergamon Press, pp967-984, 1985
[67]C.K. Soh and J. Yang, "Fuzzy controlled Genetic Algorithm search for Shape optimisation", J. Comp. Civil Eng., vol.10, \#2, pp143-151, 1996

[68]B.A. Szabo and R.L. Actis, "Finite Element Analysis in Professional practice", Comp. Meths. App. Mech. Eng., vol.133, \#3-4, pp209-228, 1996

[69]H. Takahashi and H. Shimizu, "A General Purpose Automatic Mesh Generation using Shape Recognition Techniques", in Computers in Engineering 1991, Vol. 1, (Proc. Int. Conf. ASME Int. Comp. Eng., 1991), ASME, pp519-526, 1991

[70]J.F. Thompson, Z.U.A. Warsi and C.W. Mastin, "Numerical Grid Generation, Foundations and Applications", North Holland / Elsevier, 1985

[71]B.H.V. Topping and A. Bahreininejad, "Subdomain Generation using parallel Q-state Potts Neural Networks", in Developments in Neural Networks and Evolutionary Computing for Civil and Structural Engineering, B.H.V. Topping, Ed., Civil-Comp Press, 1995

[72]G.M. Turkiyyah and S.J. Fenves, "Knowledge-Based Assistance for Finite Element Modelling", IEEE Expert, vol.11, \#3, pp23-32, 1996

[73] G.F. Uler and O.A. Mohammed, "Ancillary techniques for the practical implementation of GAs to the optimal design of electromagnetic devices", IEEE Trans. Magnetics, vol.32, \#3,, pp1194-1197, 1996

[74]S. Valliapan and T.D. Pham, "Elasto-Plastic Finite Element Analysis with Fuzzy parameters", Int. J. Num. Meths. Eng., vol.38, pp531-548, 1995

[75]M.S. Vimawala and G.M. Turkiyyah, "Computational procedures for topological shape design", Comp. Meth. App. Mech. Eng., vol.125, pp257-285, 1995

[76]S.S. Wang, "Knowledge-Based Diagnostics and Design Systems", Computers in Engineering 1991, Vol. 1, (Proc. Int. Conf. ASME Int. Comp. Eng., 1991), ASME, pp13-22, 1991

[77]G. Yagawa, Y. Mochizuki and S. Yoshimura, "Automated Structural Design based on Expert's knowledge and Fuzzy Control", Computers in Engineering 1991, Vol. 1, (Proc. Int. Conf. ASME Int. Comp. Eng., 1991), ASME, pp23-28, 1991

[78]G. Yagawa, S. Yoshimura, N. Soneda, and K. Nakao, "Automatic Two- and Three-dimensional Mesh Generation based on Fuzzy knowledge processing", Comp. Mech., vol.9 \#5, pp333-346, 1992

[79]G. Yagawa, S. Yoshimura and H. Kawai, "Automatic large-scale Mesh Generation based on Fuzzy knowledge processing and computational geometry (with a new function for Three-dimensional Adaptive remeshing)", Trans. Jap. Soc. Mech. Eng. (JSME) Part A, vol.61, \#583, pp652-659, 1995

[80]G. Yagawa, S. Yoshimura and K. Nakao, "Automatic Mesh Generation of complex geometries based on Fuzzy knowledge processing and computational geometry", Int. CAE, vol.2, \#4, pp265-280, 1995

[81] G.I. Yagawa and H. Okuda, "Finite Element Solutions with Feedback Network Mechanism through direct minimization of Energy functionals", Int. J. Num. Meths. Eng., vol.39, pp867-883, 1996

[82]K.T. Yao and A. Gelsey, "Intelligent Automated Grid Generation for numerical simulations", AI Eng. Des. Anal. Manuf., vol.10, \#3, pp215234, 1996

[83]Z. Young and I.R. Grosse, "Rule-based computational system for Automatic Finite Element modelling", in Computers in Engineering 1990, (Proc. Int. Conf. ASME Int. Comp. Eng., 1990), ASME, pp 87 94, 1990

[84]L. Zadeh, "Fuzzy Sets", Information and Control, vol.8, pp338-353, 1965

[85]O.C. Zienkiwicz, The Finite Element Method in Engineering Science, Mcgraw-Hill, 1971

[86]O.C. Zienkiwicz and J.Z. Zhu, "The three R's of engineering analysis and error estimation and adaptivity", Comp. Meths. App. Mech. Eng., vol.82, pp95-113, 1990 